\title{
Measures and Effects of Pain Management for Wound Dressing Change in Outpatient Children in Western China
}

This article was published in the following Dove Press journal: Journal of Pain Research

\author{
Yujie Wu (D) \\ Yong Zhao $\mathbb{D}^{2}$ \\ Guangyan Lin (D) ${ }^{3}$ \\ Manoj Sharma (D) ${ }^{4}$ \\ Yan Wang (D' \\ Liping Chen' \\ Liping Wu (1D'
}

'Department of Nursing, Children's Hospital of Chongqing Medical University, National Clinical Research Center for Child Health and Disorders, Ministry of Education Key Laboratory of Child Development and Disorders, Chongqing Key Laboratory of Pediatrics, Chongqing, People's Republic of China; ${ }^{2}$ School of Public Health and Management, Chongqing Medical University, Chongqing, People's Republic of China; ${ }^{3}$ Department of Outpatient Surgery, Children's Hospital of Chongqing Medical University, Chongqing, People's Republic of China; ${ }^{4}$ Environmental \& Occupational Health, University of Nevada, Las Vegas, NV, USA
Correspondence: Liping Wu Department of Nursing, Children's Hospital of Chongqing Medical University, National Clinical Research Center for Child Health and Disorders, Ministry of Education Key Laboratory of Child Development and Disorders, Chongqing Key Laboratory of Pediatrics, 136 Zhongshan 2nd Road, Yuzhong District, Chongqing, People's Republic of China $\mathrm{Tel}+86$ I3883994594

Email wulp312@I63.com
Purpose: The present study investigated the pain management of wound dressing change in outpatient children in western China, and the results may provide a reference to improve the pain management of wound dressing change.

Methods: A cross-sectional survey was performed to investigate the pain management of wound dressing change in outpatient children in western China. A total of 47 hospitals were selected via convenience sampling, and the pain management organization systems, concrete measures and barriers to adequate pain management of these hospitals were investigated.

Results: More than $70 \%$ of these hospitals had established pain management systems, analgesic drug management norms and wound care teams. Nurses were the primary providers for wound dressing change in $48.94 \%$ of the hospitals. The assessment, documentation or health education of the pain was not standard in $46.81 \%$ of the hospitals. Drug and nondrug analgesia measures were used in most hospitals, however, children did not receive adequate analgesia in $70 \%$ of the hospitals. Ibuprofen $(30.49 \%)$ and lidocaine $(29.27 \%)$ were commonly used analgesic drugs, and distraction (43.01\%) was commonly used as a non-drug analgesia measure. The top three barriers to adequate pain management were medical staff lacking analgesic knowledge (82.98\%), family members refusing to use analgesics $(61.70 \%)$ and low compliance of children $(55.32 \%)$.

Conclusion: The concrete measures for the management of wound dressing pain in children are not standardized, and the analgesic effect is poor. In order to improve the pain management of children, Standardized procedures for pain management (pain assessment, analgesia measures, pain documentation and health education) should be strictly followed during wound dressing change, and the identified barriers should be addressed.

Keywords: pain management, wound care, children

\section{Introduction}

Wound dressing pain refers to an unpleasant feeling and emotional experience related to tissue injury and the dressing change process. ${ }^{1}$ Studies in pediatric burn wounds demonstrate that the incidence of moderate pain is $66 \%$, and the incidence of severe pain is $25 \% .^{2}$ Children who experienced pain during infancy have longterm physiological, psychological, and behavioural sequelae, including pain sensitivity, excessive anxiety, social disorders, and avoidance behaviour. ${ }^{3,4}$ Ineffective pain management may also cause acute psychological distress to parents. ${ }^{5}$ Therefore, the pain management of wound dressing change in children is urgently needed. 
Unintentional falls, collisions/strikes, sprains, and cuts/ sharp instrument injuries are the predominant causes of injury. ${ }^{6}$ The incidence of injury in children ranges from $10.8 \%$ to $47.9 \%$ in China, which is on the rise, but the reason for the increase is not clear. ${ }^{6,7}$ In China, specialty wound clinics have not been popularized yet, and pain management modes differ between hospitals, pain management in wound dressing change remains challenging. In other countries, the severity of pain in children has been largely recognized, but the pain has not been adequately treated. ${ }^{8,9}$ The degree of pain is closely related to objective factors such as baseline pain, wound site, wound depth, and wound area. ${ }^{10}$ In addition, Sex, personality, temperament, previous painful experiences and family participation are all factors that affect the pain experience of children, so pain management in children is extremely difficult. ${ }^{11,12}$ Disability-adjusted life years (DALYs) is an important index to describe the burden of injury. The DALY rates of age-standardized injury in western China in 2017 were far higher than those in other regions, ${ }^{13}$ which means that the burden of injury in western China is relatively heavier.

The main determinants are knowledge and attitude in the Knowledge, Attitude and Practices (KAP) Model, which can independently predict the way nurses deal with patients' pain, and pain management knowledge is considered to be the strongest predictor of patients' pain. ${ }^{14}$ There are few studies on the pain management of wound dressing in children in China, but it has been confirmed that pediatric nurses do not have sufficient knowledge or appropriate attitude in pain management, ${ }^{15}$ therefore, we predict that the management of wound dressing pain in children in western China is not ideal, but we believe that a more specific response to these conditions will help solve the problem. The present study investigated the pain management of wound dressing change in outpatient children in western China, which may provide a reference for improving the pain management of wound dressing change.

\section{Patients and Methods}

\section{Study Design}

This was a cross-sectional survey. In China, wound clinicians include doctors and nurses. In hospitals where specialty wound clinics have been established, nurses performed wound dressing change. In hospitals where specialty wound clinics have not been established, doctors performed wound dressing change. To maintain the accuracy of the data, two people were selected from the outpatient wound dressing departments of each hospital: a nursing manager and a wound clinician. We checked the questionnaire results of the two participants in each hospital, and if there was any inconsistency, we checked with the participants. After double verification, we finally retained 47 questionnaires. Before the start of the study, we submitted an ethical application to the ethics committee (Institutional Review Board, Children's Hospital of Chongqing Medical University) and successfully obtained ethical approval, the ethical approval number is 224. All participants provided informed consent for this study. It is confirmed that this study complied with the Declaration of Helsinki.

\section{Setting}

This study was conducted in western China from June 2020 to August 2020. Western China consists of two parts: the southwest and northwest. The southwest includes five provinces, Chongqing, Sichuan, Yunnan, Guizhou and Tibet, and the northwest includes seven provinces, Shanxi, Gansu, Qinghai, Xinjiang, Ningxia, Inner Mongolia and Guangxi. The wound dressing departments we investigated can treat all types of wounds, except those requiring hospitalization.

\section{Participants}

Participants were collected by convenience sampling. Secondary and tertiary hospitals with wound dressing departments in western China were included, and two wound participants (a nursing manager and a wound clinician) in each hospital were asked to complete a questionnaire. Initially, questionnaires were distributed in a WeChat group, and 47 of the hospitals participated in the study; however, only 87 questionnaires were received. Subsequently, we reviewed the questionnaires and found that 7 nursing managers did not complete the questionnaire. We tried to contact them to complete the questionnaire. Ultimately, all the 47 hospitals completed the questionnaires.

\section{Bias}

Strict quality control measures were implemented to control the authenticity of the data. The questionnaire was anonymous, and each participant could answer only once according to the IP address. The questionnaire could not be submitted until all of the required questions were completed. 


\section{Survey Questionnaire}

A self-created questionnaire (Supplement 1) consisting of two parts, the basic information and the current situation of pain management was designed. The process of creating the questionnaire included three steps. First, the literature was searched for wound dressing pain in the database to draft the questionnaire. Second, semi-structured interviews with five wound specialist nurses were performed to improve the questionnaire. Finally, three wound care experts and two pain management experts modified the questionnaire. According to the evaluation of the five experts, the content validity of this questionnaire was 0.91 .

\section{Data Collection}

Questionnaires were distributed via Wechat to the Pediatric Nursing Group of the Chinese Medical Association, the International Wound Stoma Therapist Group, and the Southwest Wound Group. Uniform instructions were used to explain inclusion and exclusion criteria, study objectives, and study content. Participants who met the criteria were asked to complete the questionnaire. We collected information on the general characteristics of the hospitals and nursing managers, as well as information on the pain management organization systems, concrete measures (pain assessment, pain documentation, health education, analgesic methods and analgesic effect) and barriers to adequate pain management.

\section{Data Analysis}

The data were analyzed using SPSS version 25.0. Sample characteristics were summarized using basic descriptive statistics, and the counting data were expressed in percentage form. Comparisons of pain management systems and barriers to adequate pain management in different levels of hospitals were analyzed using the chi-squared test. Comparisons of dressing change measures between different wound clinicians were analyzed using the chi-squared test. $\mathrm{P}<0.05$ indicates that the difference is a statistically significant difference.

\section{Results}

\section{General Characteristics}

The general characteristics of hospitals are presented in Table 1. A total of 47 hospitals participated in the survey, and the sample included hospitals of various levels and types. Nurses are the primary providers of wound dressing change in $48.94 \%$ of the hospitals, the general characteristics of nursing managers are presented in Table 2.
Table I General Characteristics of Hospitals

\begin{tabular}{|c|c|c|}
\hline Characteristics & $\mathbf{N}$ & $\%$ \\
\hline \multicolumn{3}{|l|}{ Hospital level } \\
\hline Secondary hospital & II & 23.40 \\
\hline Tertiary hospital & 36 & 75.60 \\
\hline \multicolumn{3}{|l|}{ Hospital type } \\
\hline Children's Hospital & 4 & 8.51 \\
\hline Maternal and child health care hospital & 6 & 12.77 \\
\hline General hospital & 37 & 78.72 \\
\hline \multicolumn{3}{|l|}{ Wound clinicians } \\
\hline Doctor & 24 & 51.06 \\
\hline Nurse & 23 & 48.94 \\
\hline
\end{tabular}

Table 2 General Characteristics of Nursing Managers

\begin{tabular}{|c|c|c|}
\hline Characteristics & $\mathbf{N}$ & $\%$ \\
\hline \multicolumn{3}{|l|}{ Sex } \\
\hline Male & I & 2.13 \\
\hline Female & 46 & 97,87 \\
\hline \multicolumn{3}{|l|}{ Age } \\
\hline 21 to 30 years & 6 & 12.77 \\
\hline 31 to 40 years & 21 & 44.68 \\
\hline $4 \mid$ to 50 years & 19 & 40.43 \\
\hline More than 50 years & I & 2.13 \\
\hline \multicolumn{3}{|l|}{ Working years } \\
\hline I to 5 years & 25 & 53.19 \\
\hline 6 to 10 years & 13 & 27.66 \\
\hline II to 15 years & 3 & 6.38 \\
\hline 16 to 20 years & I & 2.13 \\
\hline More than 20 years & 5 & 10.64 \\
\hline
\end{tabular}

\section{Organizational System}

The organizational systems for the pain management of wound dressing change in outpatient children are presented in Table 3. More than $70 \%$ of hospitals had established pain management systems, analgesic drug management norms and wound care teams. There were no differences in the organizational systems of pain management between secondary and tertiary hospitals $(\mathrm{P}>0.05)$.

\section{Concrete Measures}

Concrete measures for the pain management of wound dressing change in outpatient children are presented in Table 4 . The assessment, documentation or health education of the pain was 
Table 3 Organizational Systems for Pain Management of Wound Dressing Change in Outpatient Children

\begin{tabular}{|l|l|l|l|l|}
\hline Category, $\mathbf{n}(\%)$ & Total $(\mathbf{n}=\mathbf{4 7})$ & Secondary Hospitals(n=I I) & Tertiary Hospitals(n=36) & P value \\
\hline $\begin{array}{l}\text { Pain management systems } \\
\text { Yes }\end{array}$ & $35(74.47)$ & $\begin{array}{l}8(72.73) \\
3(27.27)\end{array}$ & $\begin{array}{l}27(75.00) \\
9(25.00)\end{array}$ \\
No & $12(25.53)$ & & & 1.000 \\
\hline Analgesic drug management norms & & $8(72.73)$ & $29(80.56)$ \\
Yes & $37(78.72)$ & $3(27.27)$ & $7(19.44)$ \\
No & $10(21.28)$ & & $3(91.67)$ \\
\hline Wound care teams & & $10(90.91)$ & $3(8.33)$ \\
Yes & $43(91.49)$ & $1(9.09)$ & 1.000 \\
No & $4(8.5 I)$ & & \\
\hline
\end{tabular}

Table 4 Concrete Measures for Pain Management of Wound Dressing Change in Outpatient Children

\begin{tabular}{|c|c|c|c|c|}
\hline Category, n(\%) & $\begin{array}{l}\text { Total } \\
(n=47)\end{array}$ & $\begin{array}{l}\text { Doctors } \\
(n=24)\end{array}$ & $\begin{array}{l}\text { Nurses } \\
(n=23)\end{array}$ & $P$ value \\
\hline $\begin{array}{l}\text { Pain assessment } \\
\text { Yes } \\
\text { No }\end{array}$ & $\begin{array}{l}25(53.19) \\
22(46.81)\end{array}$ & $\begin{array}{l}12(50.00) \\
12(50.00)\end{array}$ & $\begin{array}{l}13(56.52) \\
10(43.48)\end{array}$ & 0.654 \\
\hline $\begin{array}{l}\text { Pain documentation } \\
\text { Yes } \\
\text { No }\end{array}$ & $\begin{array}{l}24(51.06) \\
23(48.94)\end{array}$ & $\begin{array}{l}12(50.00) \\
12(50.00)\end{array}$ & $\begin{array}{l}\text { I2(52.17) } \\
\text { II (47.83) }\end{array}$ & 0.882 \\
\hline $\begin{array}{l}\text { Pain health education } \\
\text { Yes } \\
\text { No }\end{array}$ & $\begin{array}{l}31(65.96) \\
16(34.04)\end{array}$ & $\begin{array}{l}14(58.33) \\
10(41.67)\end{array}$ & $\begin{array}{l}17(73.91) \\
6(26.09)\end{array}$ & 0.260 \\
\hline $\begin{array}{l}\text { Drug analgesia } \\
\text { Yes } \\
\text { No }\end{array}$ & $\begin{array}{l}4 \mid(87.23) \\
6(12.76)\end{array}$ & $\begin{array}{l}22(91.67) \\
2(8.33)\end{array}$ & $\begin{array}{l}19(82.61) \\
4(17.39)\end{array}$ & 0.416 \\
\hline $\begin{array}{l}\text { Non-drug analgesia } \\
\text { Yes } \\
\text { No }\end{array}$ & $\begin{array}{l}45(95.74) \\
2(4.26)\end{array}$ & $\begin{array}{l}22(91.67) \\
2(8.33)\end{array}$ & $\begin{array}{l}23(100.00) \\
0(0.00)\end{array}$ & 0.489 \\
\hline $\begin{array}{l}\text { Insufficient analgesia } \\
\text { Yes } \\
\text { No }\end{array}$ & $\begin{array}{l}36(76.60) \\
\text { II (23.40) }\end{array}$ & $\begin{array}{l}18(75.00) \\
6(25.00)\end{array}$ & $\begin{array}{l}18(78.26) \\
5(21.74)\end{array}$ & 0.792 \\
\hline
\end{tabular}

not standard in $46.81 \%$ of the hospitals (22/47). Drug and nondrug analgesia measures (the mode of analgesia can be oral analgesics or local anesthesia, clinicians prescribe drugs according to the patient's condition) were used in most of the hospitals; however, children did not receive adequate analgesia in $70 \%$ of the hospitals. Ibuprofen $(30.49 \%)$ and lidocaine (29.27\%) were commonly used analgesic drugs (Figure 1), and distraction (43.01\%) was a commonly used non-drug analgesia measure (Figure 2). There were no significant differences in concrete measures of pain management between doctors and nurses $(\mathrm{P}>0.05)$.

\section{Barriers to Adequate Pain Management}

The barriers to adequate pain management are presented in Table 5. The top three barriers to adequate pain management were medical staff lacking analgesic knowledge $(82.98 \%)$, family members refusing to use analgesics $(61.70 \%)$ and low compliance of children (55.32\%). There was no difference in the barriers to adequate pain management of wound dressing change between secondary and tertiary hospitals $(\mathrm{P}>0.05)$.

\section{Discussion}

There is an obvious difference in developing countries between what could be done to relieve pain and what is actually being achieved, which is called "the treatment gap". ${ }^{16}$ The major finding of our survey was that the organizational system of pain management in wound dressing change was relatively good, but the concrete measures need to be improved, which is consistent with the findings of previous study. ${ }^{16}$ The incidence of pain is high worldwide, but the burden of wound dressing change and pain management is relatively heavier in China, which is a developing country with a very large population base, especially in western China. ${ }^{13,17}$ Patient-centered nursing has always been the core of nursing practice, ${ }^{18}$ but clinical staff tend to focus more on the effect of wound treatment rather than the pain, so more attention should be paid to pain management.

The systematic training of wound specialist nurses started relatively late in China. It was only in 2010 that the first international training school for wound stoma incontinence was established, and then wound specialist nursing was gradually established. A quality evaluation of wound dressing change among African nurses shows that not only the quality of wound repair but also the 


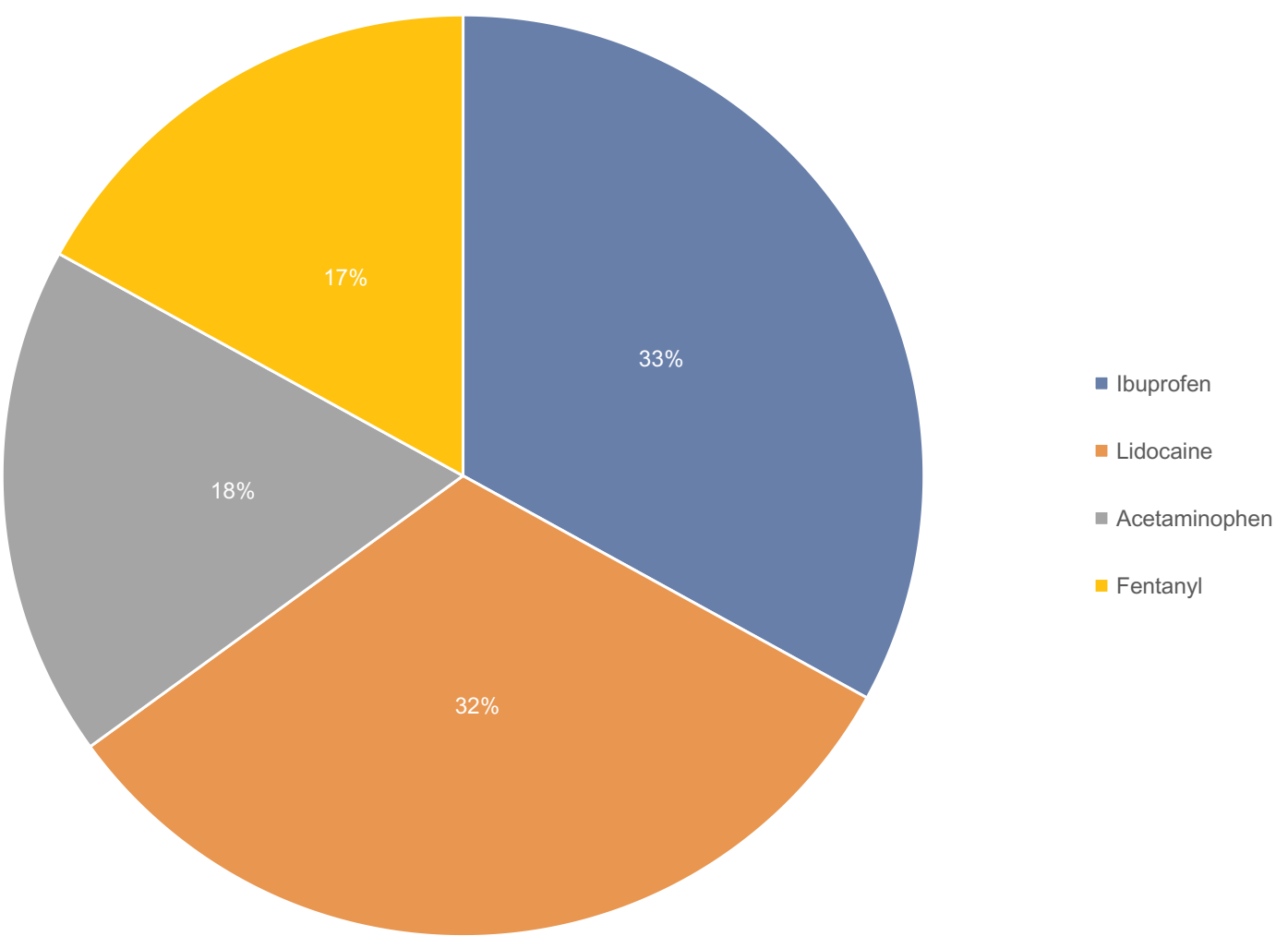

Figure I Commonly used analgesics.

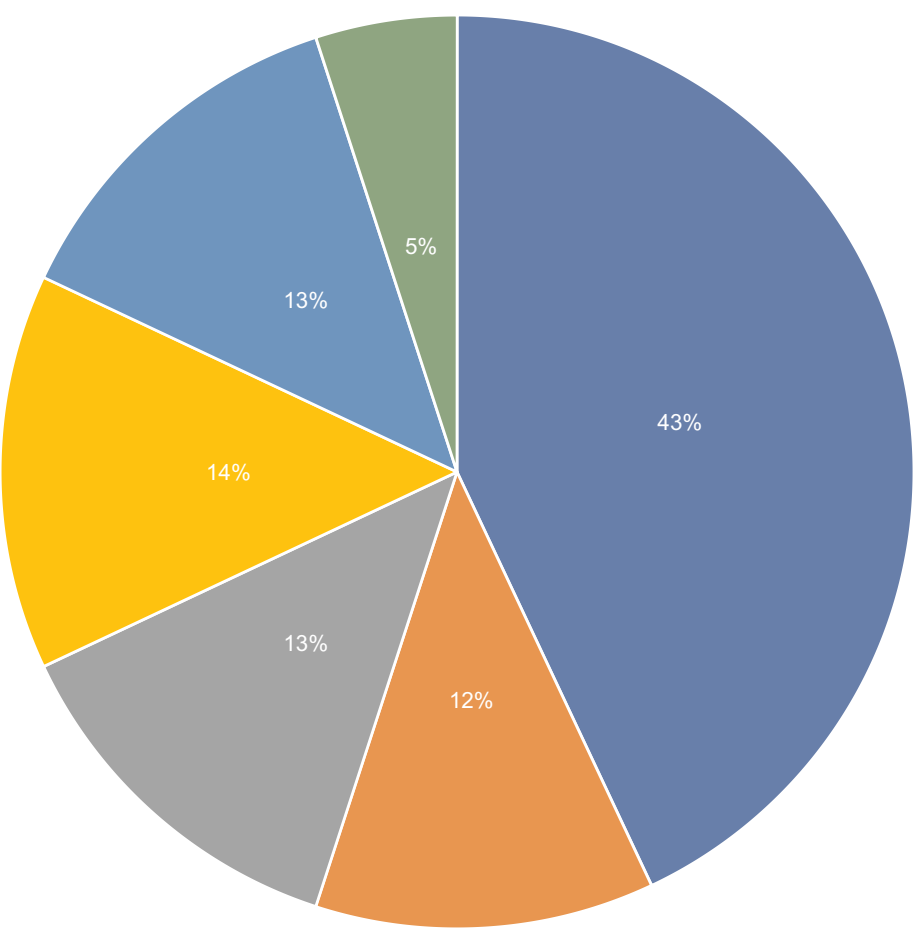

- Distraction

- Cognitive behavioral therapy

- Sweetener

- Non-nutritive sucking

- Breast-feeding

- Other

Figure 2 Commonly used non-drug analgesia. 
Table 5 Barriers to Adequate Pain Management of Wound Dressing Change in Outpatient Children

\begin{tabular}{|l|l|l|l|l|}
\hline Barriers to Adequate Pain Management, $\mathbf{n}(\%)$ & Total $(\mathbf{n}=\mathbf{4 7})$ & $\begin{array}{l}\text { Secondary Hospitals } \\
(\mathbf{n = 1} \text { I) }\end{array}$ & $\begin{array}{l}\text { Tertiary Hospitals } \\
(\mathbf{n = 3 6 )}\end{array}$ & P value \\
\hline Medical staff lack analgesic knowledge & $39(82.98)$ & $9(81.82)$ & $30(83.33)$ & 1.000 \\
Family members refuse to use analgesics & $29(61.70)$ & $8(72.73)$ & $21(58.33)$ & $17(47.22)$ \\
The compliance of children is low & $26(55.32)$ & $9(81.82)$ & $20(55.56)$ & 0.613 \\
The workload of medical staff is heavy & $24(51.06)$ & $4(36.36)$ & $17(47.22)$ & 0.094 \\
Managers ignore pain management & $20(42.55)$ & $3(27.27)$ & $14(38.89)$ & 0.201 \\
Adverse reactions of analgesics & $21(44.68)$ & $7(63.64)$ & & 0.272 \\
\hline
\end{tabular}

application of aseptic rules is very poor. ${ }^{19}$ Our survey revealed that nurses performed wound dressing change primarily in $48.94 \%$ of the hospitals and there was no difference in the pain management of wound dressing change between doctors and nurses. This result suggests that wound care developed rapidly in China and achieved certain clinical benefits. However, we cannot ignore that the pain management of wound dressing change is not ideal on the whole. In Finland, nurses do not routinely use pain assessment scales in clinical practice. ${ }^{20}$ In Spain, there is an average of 6.6 invasive operations a day on newborns, but analgesic interventions are recorded for only $32.5 \%$ of these procedures. ${ }^{21}$ In our study, more than half of the hospitals did not assess or document wound dressing pain, and $34.04 \%$ of the hospitals did not provide pain health education. Anyway, the pain management of wound dressing pain is a common problem in clinical practice. Pain management procedures include pain assessment, analgesic measures, pain documentation and health education. The International Association for the Study of Pain (IASP) required that evidence-informed pain assessment should be taken, and the responses should be documented. ${ }^{22}$ However, there is still a substantial gap between the current situation of pain management and the proposal of the IASP. A basic principle is that pain must be assessed and documented in a consistent and informed manner. ${ }^{23}$ Therefore, it is essential to standardize the pain assessment process and ensure the implementation of pain management measures.

Drug and non-drug analgesia measures were used in most hospitals in our study, but $76.7 \%$ of the hospitals provided insufficient analgesia during wound dressing change. Therefore, the effectiveness of analgesic measures needs to be improved. Our study revealed that the most commonly used analgesics for wound dressing change in outpatient children were ibuprofen (a nonsteroidal anti-inflammatory drug) and lidocaine (a local anaesthetic). The main analgesics used in the United States, Iraq and Afghanistan are opioids. ${ }^{24,25}$ Opioids and non-steroidal anti-inflammatory drugs are safe and effective wound painkillers considering the contraindications, and evidence for the effectiveness of local anaesthetics is limited. ${ }^{26}$ This result suggests that wound clinicians should reasonably chose the drugs, and the pain responses of children should be closely observed. Of all the methods of non-drug analgesia, distraction was highly respected, and the utilization rate of distraction was as high as $43 \%$ in the survey. It has been confirmed that distraction can improve the rate of burn reepithelialization, and the faster wounds heal, the less likely they scar and the less likely these children are to experience lifelong consequences. ${ }^{27}$ Distraction can also achieve excellent clinical results in relieving pain, reducing medical costs and improving work efficiency. ${ }^{28,29}$ The analgesic effect of active distraction (eg, interactive toys, situational games, and virtual reality) is better than that of passive distraction (eg, sight, hearing, and taste), ${ }^{30,31}$ and the efficacy of distraction also depends on the children's attention. ${ }^{32}$ Therefore, it is necessary to take children's attention characteristics into consideration to choose distraction methods.

Our research suggests that the major factors affecting the pain management of wound dressing change are medical staff lacking analgesic knowledge, family members refusing to use analgesics and low compliance of children, which is similar to the findings of previous study. ${ }^{33}$ Medical staff lacking analgesic knowledge is a worldwide problem. ${ }^{34-36}$ To narrow the knowledge gap and to realize the homogenization of wound care, there is an urgent need to implement high-quality educational programmes on pain management. The drug compliance of children is significantly related to the children's trust in their parents, many parents are worried about the side effects of analgesics, which affects the quality of the 
children's pain management. ${ }^{37,38}$ Health education on pain is extremely important to change the analgesia concept of children and parents. However, pain health education was only performed in $65.96 \%$ of the hospitals in our study. Generally, the pain management of children necessitates the joint efforts of wound clinicians, parents and children, and wound clinicians need to learn more about pain management and apply it to clinical practice.

There are some shortcomings in this study, such as the small sample, but each sample was verified by two participants, which is sufficient to reflect the current situation of the hospitals investigated. In addition, no statistically significant results were found in this study. For example, there was no significant difference in pain management between doctors and nurses, but the years of wound dressing change by nurses were relatively late in China, which is sufficient to show the progress of wound care in China.

\section{Conclusion}

This cross-sectional study presented the objective situation of pain management of wound dressing change in outpatient children in western China. The organizational systems of pain management were relatively good, but the concrete measures and the analgesic effect were not ideal. For the contradiction between the organizational systems and concrete measures, whether the organizational systems did not meet the needs of the clinical practice, or the organizational systems were not actually implemented requires further examination. The cooperation of wound clinicians, family members and patients may help to reduce these barriers. More importantly, it is necessary to strengthen the education of wound clinicians with respect to pain management.

The present study analyzed the challenges faced by the pain management of wound dressing in outpatient children, and the results may provide a reference for government health policy makers and hospital managers to improve the quality of pain management.

\section{Acknowledgments}

This study was funded by the 13th Five-Year Key Discipline of Nursing Science of Chongqing Education Commission (2019hlxk09) and Nursing Hospital-level Scientific Research Project of Children's Hospital of Chongqing Medical University (CHCQMU2019.20). Special thanks is given to all the hospitals and respondents who participated in the survey.

\section{Disclosure}

The authors report no conflicts of interest in this work.

\section{References}

1. Obilor HN, Adejumo PO, Ilesanmi RE. Assessment of patients" wound-related pain experiences in University College Hospital, Ibadan, Nigeria. Int Wound J. 2016;13(5):697-704. doi:10.1111/ iwj. 12349

2. de Jong AEE, Bremer M, Komen RV, et al. Pain in young children with burns: extent, course and influencing factors. Burns. 2014;40 (1):38-47. doi:10.1016/j.burns.2013.09.017

3. Valeri BO, Ranger M, Chau CMY, et al. Neonatal Invasive Procedures Predict Pain Intensity at School Age in Children Born Very Preterm. Clin J Pain. 2016;32(12):1086-1093. doi:10.1097/ AJP.0000000000000353

4. Ali S, McGrath T, Drendel AL. An Evidence-Based Approach to Minimizing Acute Procedural Pain in the Emergency Department and Beyond. Pediatr Emerg Care. 2016;32(1):36-42.

5. Brown EA, Young AD, Kimble R, et al. The role of parental acute psychological distress in paediatric burn re-epithelialization. Observational Study. 2019;4(24):876-895.

6. Fang Y, Zhang X, Chen W, et al. Epidemiological characteristics and burden of childhood and adolescent injuries: a survey of elementary and secondary students in Xiamen, China. BMC Public Health. 2015;15(1):357.

7. Ma S, Jiang M, Wang F, et al. Left-Behind Children and Risk of Unintentional Injury in Rural China-A Cross-Sectional Survey. Int J Environ Res Public Health. 2019;16(3):403.

8. Pardesi O, Fuzaylov G. Pain Management in Pediatric Burn Patients: review of Recent Literature and Future Directions. J Burn Care Res. 2017;38(6):335-347.

9. Frescos N. Assessment of pain in chronic wounds: a survey of Australian health care practitioners. Int Wound J. 2018;15 (6):943-949.

10. Holbert MD, Kimble RM, Jones LV, et al. Risk factors associated with higher pain levels among pediatric burn patients: a retrospective cohort study. Reg Anesth Pain Med. 2020;2020. doi:10.1136/rapm2020-101691

11. Manocha S, Taneja N. Assessment of paediatric pain: a critical review.. J Basic Clin Physiol Pharmacol. 2016;27(4):323-331. doi:10.1515/jbcpp-2015-0041

12. Pancekauskaite G, Jankauskaite L. Paediatric Pain Medicine: pain Differences, Recognition and Coping Acute Procedural Pain in Paediatric Emergency Room. Medicina. 2018;54(6):94. doi:10.3390/ medicina54060094

13. Zhou M, Wang H, Zeng X, et al. Mortality, morbidity, and risk factors in China and its provinces, 1990-2017: a systematic analysis for the Global Burden of Disease Study 2017. Lancet. 2019;394 (10204):1145-1158. doi:10.1016/S0140-6736(19)30427-1

14. Alzghoul BI, Abdullah NAC. Pain Management Practices by Nurses: an Application of the Knowledge, Attitude and Practices (KAP) Model. Glob J Health Sci. 2015;8(6):154-160. doi:10.5539/gjhs. v8n6p154

15. Hua Y, Zhang Q, Ting W, et al. Pediatric Nurse Practitioners Knowledge and Attitudes Regarding Pain Management Study in Central China. J Contin Educ Nurs. 2019;50(6):275-281. doi:10.3928/00220124-20190516-08

16. Bond M. Pain education issues in developing countries and responses to them by the International Association for the Study of Pain. Pain Res Manag. 2011;16(6):404-406. doi:10.1155/2011/654746

17. Jiang Y, Xia L, Jia L, et al. Survey of Wound-Healing Centers and Wound Care Units in China. Int J Low Extrem Wounds. 2016;15 (3):274-279. doi:10.1177/1534734614568667 
18. Ortiz MR. Patient-Centered Care: nursing Knowledge and Policy. Nurs Sci Q. 2018;31(3):291-295. doi:10.1177/0894318418774906

19. Badri T, Maghrebi H, Hamdi A, et al. Assessment of the quality of the change of surgical wound dressings by the nursing staff in a university hospital of Tunis. Tunis Med. 2018;6(96):366-370.

20. Pölkki T, Korhonen A, Laukkala H, et al. Nurses' perceptions of pain assessment and management practices in neonates: a cross-sectional survey. Scand J Caring Sci. 2018;32(2):725-733. doi:10.1111/ scs. 12503

21. Sposito NPB, Rossato LM, Bueno M, et al. Assessment and management of pain in newborns hospitalized in a Neonatal Intensive Care Unit: a cross-sectional study. Rev Latino Am De Enfermagem. 2017;25:e2931-e2931. doi:10.1590/1518-8345.1665.2931

22. World Health Organization (WHO)[homepage on the Internet]. THE CHILDKIND INITIATIVE: a program to reduce pain in child health facilities worldwide; 2010. Available from: https://www.iasp-pain. org/NRGPI?navItemNumber=889. Accessed April 14, 2010..

23. Jones ML, Greenwood M, Bielby A. Living with wound-associated pain: impact on the patient and what clinicians really think. $J$ Wound Care. 2010;19(8):340-345. doi:10.12968/jowc.2010.19.8.77712

24. Myers R, Lozenski J, Wyatt M, et al. Sedation and Analgesia for Dressing Change: a Survey of American Burn Association Burn Centers. J Burn Care Res. 2017;38(1):e48-e54. doi:10.1097/ BCR.0000000000000423

25. Schauer SG, Arana AA, Naylor JF, et al. Prehospital Analgesia for Pediatric Trauma Patients in Iraq and Afghanistan. Prehospital Emergency Care. 2018;22(5):608-613. doi:10.1080/ 10903127.2018.1428839

26. Sullivan D, Lyons M, Montgomery R, et al. Exploring Opioid-Sparing Multimodal Analgesia Options in Trauma: a Nursing Perspective. J Trauma Nurs. 2016;23(6):361-375. doi:10.1097/JTN.0000000000000250

27. Brown NJ, Kimble RM, Rodger S, et al. Play and heal: randomized controlled trial of Ditto ${ }^{\mathrm{TM}}$ intervention efficacy on improving reepithelialization in pediatric burns. Burns. 2014;40(2):204-213. doi:10.1016/j.burns.2013.11.024

28. Miller K, Rodger S, Bucolo S, et al. Multi-modal distraction. Using technology to combat pain in young children with burn injuries. Burns. 2010;36(5):647-658. doi:10.1016/j.burns.2009.06.199
29. Brown NJ, David M, Cuttle L, et al. Cost-Effectiveness of a Nonpharmacological Intervention in Pediatric Burn Care. Value Health. 2015;18(5):631-637. doi:10.1016/j.jval.2015.04.011

30. Attar RH, Baghdadi ZD. Comparative efficacy of active and passive distraction during restorative treatment in children using an iPad versus audiovisual eyeglasses: a randomised controlled trial. Eur Arch Paediatr Dent. 2015;16(1):1-8. doi:10.1007/s40368-014-0136$\mathrm{x}$

31. Al-Ghamdi NA, Meyer WJ, Atzori B. Virtual Reality Analgesia With Interactive Eye Tracking During Brief Thermal Pain Stimuli: a Randomized Controlled Trial (Crossover Design). Front Hum Neurosci. 2020;13:467. doi:10.3389/fnhum.2019.00467

32. Dancela R, Liles EA, Fiore D, et al. Acute Pain Management in Hospitalized Children. Rev Recent Clin Trials. 2017;4(12):277-283.

33. Hu J, Ruan H, Li Q, et al. Barriers and facilitators to effective procedural pain treatments for pediatric patients in the Chinese context: a qualitative descriptive study. J Pediatric Nurs. 2020;54:78-85. doi:10.1016/j.pedn.2020.06.004

34. Khalil H, Mashaqbeh M. Areas of Knowledge Deficit and Misconceptions Regarding Pain among Jordanian Nurses. Pain Manage Nurs. 2019;20(6):649-655. doi:10.1016/j.pmn.2019.02.010

35. Ishak S, Nfe F, Sz SZ, et al. Neonatal pain: knowledge and perception among pediatric doctors in Malaysia. Pediatr Int. 2019;61(1):67-72. doi:10.1111/ped.13724

36. Peirce D, Corkish V, Lane M, et al. Nurses' Knowledge and Attitudes Regarding Pediatric Pain Management in Western Australia. Pain Manag Nurs. 2018;19(6):707-717.

37. Twycross AM, Williams AM, Bolland RE, et al. Parental attitudes to children's pain and analgesic drugs in the United Kingdom. J Child Health Care. 2015;19(3):402-411.

38. Nagae M, Nakane H, Honda S, et al. Factors affecting medication adherence in children receiving outpatient pharmacotherapy and parental adherence. $J$ Child Adolesc Psychiatr Nurs. 2015;28 (2):109-117.
Journal of Pain Research

\section{Publish your work in this journal}

The Journal of Pain Research is an international, peer reviewed, open access, online journal that welcomes laboratory and clinical findings in the fields of pain research and the prevention and management of pain. Original research, reviews, symposium reports, hypothesis formation and commentaries are all considered for publication. The manuscript management system is completely online and includes a very quick and fair peer-review system, which is all easy to use. Visit http:// www.dovepress.com/testimonials.php to read real quotes from published authors. 